\title{
Genetic Twists of Fate Stanley Fields and Mark Johnston
}

\author{
MIT Press, Cambridge, MA, 2010, \$24.95
}

\author{
Robert Resta
}

Received: 21 March 2011 /Accepted: 23 March 2011 / Published online: 20 April 2011

(C) National Society of Genetic Counselors, Inc. 2011

There is much talk these days about the dawn of The Genomic Era in which disease prevention and therapeutics will be based on individualized genetic risk assessment, letting us all lead happy, healthy lives guided from cradle to grave by the knowledge of our unique GTCA sequences. While these predictions are perhaps a tad optimistic and guided more by enthusiasm than hard data, medical genetics has undeniably grown from a niche practiced by a handful of specialists to being integrated into almost every aspect of medicine. Just try to find a current of issue of a medical journal of any stripe that does not have an article about genetics. Yet studies demonstrate a shocking lack of genetic knowledge among many healthcare providers and the general public.

Genetic Twists of Fate tries to bridge this knowledge gap for the general public. Let me be clear up front-while genetic counselors may find nuggets of interest in this book, we are definitely not its target audience. Instead, the authors aim to provide the lay reader with a broad overview of genetic principles and genomic medicine by focusing on specific topics such as hereditary enzyme defects, Alzheimer disease, cancer genetics, stem cells, heritability of behavior, ALS, macular degeneration, coumadin metabolism, race, and evolution.

Along the way, authors Fields and Johnston attempt to perk up the reader's interest by highlighting popular culture icons who have been affected by genetic disease or variants. I found some guilty gossipy pleasure in these asides but the figures they have chosen to focus on reflect the authors' ages and interests. Many readers under 50 may be less captivated than the authors by Rita Hayworth's early onset Alzheimer's disease, Isaac Asimov's death from transfusion-acquired HIV, or Arthur Ashe's heart disease. Nothing wrong with the stories about these folks, but perhaps not the best choices if you are looking to engage a broader, younger audience. Along the same lines, the simple illustrations, while perfectly adequate to the task at hand, have a textbook-y feel to them, nor does the book include photographs of the historical and contemporary figures whose stories are being related (how could anyone pass up an opportunity to publish a photo of the beautiful Rita Hayworth in a scientific book?).

This is a book to suggest to patients or friends interested in a short, broad overview of genetics and genetic disease, delivered in a straight-forward manner that's only slightly professorial and not overwhelming. However, if you are looking for a book to help patients better choose and understand their own genetic tests and their implications, you might be better off recommending The Genome Book: A Must-Have Guide to Your DNA for Maximum Health, written by genetic counselor Vicke Venne and journalist April Lynch. 